$$
\text { THE ISOLATION OF HYDRAZINE, } \stackrel{\mathrm{NH}}{\mathrm{NH}_{2}} .
$$

I $\mathrm{N}$ the June of 1887 , Prof. Curtius, of the University of Erlangen, announced, in the Berichte of the Berlin Chemical Society, the important fact that he had succeeded in preparing the hydride of nitrogen, di-amidogen or hydrazine, and an account of his preliminary experiments was given in NATURE (vol. xxxvi. p. 185). Since that time several further contributions to the history of the base and its salts have been published by Drs. Curtius and Jay (see NATURE, vol. xxxix. p. 377, and vol. xli. p. 547), and the work is now completed by the publication, in the current number of the Journal fïr praktische Chemie, by Urs. Curtius and Schulz, of full details of the perfected methods of preparation of the base and its most important salts, together with the results of determinations of its vapour density and of its molecular weight when dissolved in water.

It will doubtless be remembered that free hydrazine was supposed by Prof. Curtius to be a gas, possessing such an exceedingly powerful affinity for water that it was found almost impossible to isolate it from its hydrate. This difficulty has since to a large extent been overcome, and the nature of the gas itsclf more certainly ascertained. The hydrate is a very definite compound of the composition $\mathrm{N}_{2} \mathrm{H}_{4} \cdot \mathrm{H}_{2} \mathrm{O}$, and it serves as the best starting-point for the preparation both of the free gaseous hydrazine itself and of the salts of the base.

\section{Preparation of Hydrazine Hydrate.}

Hydrazine hydrate is best prepared by distilling the sulphate, $\mathrm{N}_{2} \mathrm{H}_{4} . \mathrm{H}_{2} \mathrm{SO}_{4}$, with alkalies. Hydrazine sulphate is a beautifully crystalline salt consisting of colourless rhombic tables, the macropinacoid being the most fully developed face. It is obtained most readily by the method of Curtius and Jay from triazoacetic acid.

The perfected method of preparing hydrazine hydrate from these crystals of the sulphate is as follows:-About one hundred grams of pure caustic potash are dissolved in 250 grams of water. After cooling, a hundred grams of the finely powdered crystals of the sulphate are added, and the mixture subjected to distillation. Owing to the tremendously active properties of hydrazine, the distillation apparatus requires to be constructed throughout of pure silver. The form employed by Prof. Curtius consists of a silver flask of about a litre capacity, which can be screwed in a gas-tight manner to the silver condenser. The connecting-tube between the flask and the condenseris bent into a double $U$ shape, so that particles cannot possibly be projected from the flask into the condenser ; a thermometer is inscrted in the limb of the $U$ nearest the condenser. The flask is protected from the flame by an asbestos cushion. Cork and india-rubber connections must be rigorously excluded, as hydrazine most energetically attacks them. When the powdered sulphate is added to the strong potash solution in the flask, considerable heat is generated and the thermometer rapidly rises. Heat is then carefully applied, and liquid begins to distil. As soon as the thermometer indicates $119^{\circ} \mathrm{C}$., the boiling-point of hydrazine hydrate, the receiver is changed. It is then found that the temperature remains constant at II $9^{\circ}$ until almost the last drop, the liquid distilling at this temperature being almost pure $\mathrm{N}_{2} \mathrm{H}_{4} \cdot \mathrm{H}_{2} \mathrm{O}$. The distillate collected before the thermometer reached $11^{\circ}$, generally amounting to about 250 c.c., should then be fractioned. It is a most curious fact that, although the boiling-points of water and hydrazine hydrate are so close together, only very small quantities of the latter are carried over by steam. More than two-thirds of the 250 c.c. pass over on redistillation before the mercury rises above $100^{\circ}$.

$$
\text { NO. I IO5, VOL. 43] }
$$

Between $100^{\circ}$ and $106^{\circ}$ a distillate is obtained which does not contain more than I per cent. of hydrazine. The $106^{\circ}-117^{\circ}$ fraction contains still only about i I per cent., while that passing over between $117^{\circ}$ and $119^{\circ}$ contains $60-62.5$ per cent. of hydrazine. The liquid obtained in the first distillation, while the thermometer indicated I $19^{\circ}$, contains 64 per cent. of the free base, the theoretical quantity for the formula $\mathrm{N}_{2} \mathrm{H}_{4} \cdot \mathrm{H}_{2} \mathrm{O}$. From one hundred grams of hydrazine sulphate 36 grams of the pure hydrate are obtained in a careful experiment.

As regards the analysis of the hydrate, the amount of base, $\mathrm{N}_{2} \mathrm{H}_{4}$, may be determined by means of standard sulphuric acid, all the usual indicators except phenol phthalein being available. The nitrogen and hydrogen may be estimated by combustion with copper oxide, and the nitrogen also by reduction of platinum chloride, the whole of the nitrogen being evolved in the free state in accordance with the equation

$$
\mathrm{N}_{2} \mathrm{H}_{1} \cdot \mathrm{H}_{2} \mathrm{O}+2 \mathrm{PtCl}_{1}=2 \mathrm{PtCl}_{2}+{ }_{4} \mathrm{HCl}+\mathrm{H}_{2 .} \mathrm{O}+\mathrm{N}_{2 .}
$$

Molecular Composition of Hydrazine Hydrate.

The vapour density of the compound has been determined by Hofmann's method in the Torricellian vacuum, using a jacket of steam. The molecular weight corresponding to the formula $\mathrm{N}_{2} \mathrm{H}_{4} \cdot \mathrm{H}_{2} \mathrm{O}$ is 50 . The numbers obtained from three such density determinations were $48.79,51.67$, and 49.48 , showing that the simple formula $\mathrm{N}_{2} \mathrm{H}_{4} \cdot \mathrm{H}_{2} \mathrm{O}$ expresses in all probability the molecular condition. When vapour density determinations at ordinary pressure by Victor Meyer's method are carried out, some rather surprising results are obtained. At the temperature of boiling aniline $\left(183^{\circ}\right)$ the numbers 28.25 and 23.52 were obtained, about half those at $100^{\circ}$ in vacuio; it appears probable, therefore, that at this temperature and under ordinary pressure complete dissociation into $\mathrm{N}_{2} \mathrm{H}_{4}$ and $\mathrm{H}_{2} \mathrm{O}$ eccurs, the molecules of the hydrazine existing side by side with those of water vapour without combination. At higher temperatures the molecular weight appears to increase again, a phenomenon which requires further investigation.

The molecular weight of the hydrate dissolved in water has also been determined by Raoult's method, by noticing the lowering of the freezing-point of water brought about by dissolving a small quantity of the hydrate in it. The numbers obtained from three experiments were $6973,707 \mathrm{I}$, and $7 \mathrm{I}^{\circ} 25$, corresponding almost exactly to a hydrate of the formula $\mathrm{N}_{2} \mathrm{H}_{1} \cdot 2 \mathrm{H}_{2} \mathrm{O}$.

It appears, therefore, from the above experimental results, that the vaporized hydrate posesses the composition $\mathrm{N}_{2} \mathrm{H}_{4} \cdot \mathrm{H}_{2} \mathrm{O}$. At $183^{\circ}$ these molecules appear to dissociate into free hydrazine and water vapour. When the hydrate dissolves in water, it takes up another molecule of water, becoming $\mathrm{N}_{2} \mathrm{H}_{4} \cdot 2 \mathrm{H}_{2} \mathrm{O}$.

\section{Properties of Hydrazine Hydrate.}

Hydrazine hydrate is a colourless, highly-refractive, but not very mobile, liquid, which fumes when brought into the air. In closed vessels it may be preserved unaltered for any length of time. Its odour is quite different from that of ammonia, and is indeed comparatively weak compared with that of free gaseous hydrazine. It tastes like alkalies, and leaves on the tongue a burning sensation. It possesses strongly corrosive properties, at once destroying cork or caoutchouc. The boiling liquid rapidly attacks glass. It is hygroscopic, and also extracts carbon dioxide from the atmosphere. It mixes with water and alcohol in all proportions, but not with ether, chloroform, or benzene. It solidifies when surrounded by a mixture of solid carbon dioxide and ether to a mass of leaf-like crystals, which again liquefy from some reason or other below $-40^{\circ}$. Although hygroscopic, when a drop of the liquid is allowed to fall into a cylinder of water, it remains for a long time at the bottom without mixing. 
The specific gravity of the pure liquid of boiling-point I I $8^{\circ} 5$ (corr.) is 1.0305 at $21^{\circ}$.

A peculiar phenomenon is noticed during the distillation of hydrazine hydrate mixed with water. When a certain stage of concentration is reached, the drops falling from the end of the condenser into the glass receiver before dissolving take the form of extended filaments, often fine threads, which do not adhere to the walls of the receiver. The liquid hydrate reacts very strongly alkaline to vegetable colouring matters. Its reducing properties, as mentioned in the earlier notes in NATURE before referred to, are extraordinarily marked, most of the ordinary salt solutions of silver, gold, platinum, ferric iron, and cupric copper being reduced, and in the case of silver beautiful metallic mirrors deposited. Mercuric oxide reacts with it so energetically as to bring about an immediate explosion.

\section{Free Gaseous Hydrazine.}

Owing to the extreme affinity of hydrazine for water to form the hydrate, the free base is only liberated from the latter compound with the greatest difficulty. When the liquid hydrate is dropped upon barium oxide in a fractionating flask, the mass becomes very hot; but on distilling, almost the total quantity of hydrazine hydrate distils over unchanged. By repeated distillation over recently ignited baryta, a portion of the water in the hydrate is certainly retained, however, and the distillate fumes more strongly in the air. When the mixture of hydrate and baryta is beated in a sealed tube to $100^{\circ} \mathrm{C}$. the reaction goes much further; and when the temperature is increased to $170^{\circ}$, at which temperature under ordinary pressure hydrazine hydrate is dissociated into $\mathrm{N}_{2} \mathrm{H}_{4}$ and $\mathrm{H}_{2} \mathrm{O}$, the decomposition is complete, the tube containing barium hydrate and gaseous hydrazine at high pressure. When the end of the tube is softened at the blowpipe, a tremendous rush of the free gas occurs, forming as it escapes a long rod-like white cloud with the moisture of the air, and rendering the atmosphere almost unbearable by its fearfully penetrating odour, compared with which that of the liquid hydrate is extremely weak. Owing to the difficulty of collecting and preserving such an active gas, which reminds one irresistibly of fluorine, Prof. Curtius has not been able to experiment further with it.

\section{Action of Halogens and Hulogen Acids upon Hydrazine} Hydratc.

The halogen salts of hydrazine have been examined in great detail, and present some most interesting phenomena, throwing considerable light upon the constitution of the base.

Two kinds of salts are found capable of existing-monosalts of the type $\mathrm{N}_{2} \mathrm{H}_{4}$. HR, where $\mathrm{R}$ represents a halogen element, and di-salts of the type $\mathrm{N}_{2} \mathrm{H}_{4} \cdot 2 \mathrm{HR}$.

When the hydrate diluted with water is mixed with hydrofluoric acid, the dihydrofluoride, $\mathrm{N}_{2} \mathrm{H}_{4} \cdot 2 \mathrm{HF}$, is obtained in crystals belonging to the regular system melting at $105^{\circ}$. This difluoride appears to sublime unchanged. It may also be obtained by adding hydrofuoric acid to the alcoholic solution of the hydrate, and then precipitating with ether.

The dihydrochloride, $\mathrm{N}_{2} \mathrm{H}_{4} \cdot 2 \mathrm{HCl}$, is similarly obtained when hydrazine hydrite is evaporated with hydrochloric acid, or by action of hydrochloric acid upon the alcoholic solution of the hydrate. It is also formed when gaseous chlorine is led into a flask containing hydrazine hydrate; after a féw minutes' passage of the gas, the separation of beautiful octahedrons begins, and bubbles of nitrogen escape. The reaction is as follows :-

$3\left(\mathrm{~N}_{2} \mathrm{H}_{4} \cdot \mathrm{H}_{2} \mathrm{O}\right)+2 \mathrm{Cl}_{2}=2\left(\mathrm{~N}_{2} \mathrm{H}_{4} \cdot 2 \mathrm{HCl}\right)+3 \mathrm{H}_{2} \mathrm{O}+\mathrm{N}_{2}$.

It is interesting to note that this same chloride was obtained by Curtius and Jay by boiling a compound which NO. I IO5, VOL. 43] they prepared, termed benzalazine, $\mathrm{N}_{2}\left(\mathrm{CH} \cdot \mathrm{C}_{6} \mathrm{H}_{5}\right)_{2}$, with hydrochloric acid--

$\mathrm{N}_{2}\left(\mathrm{CH} . \mathrm{C}_{6} \mathrm{H}_{5}\right)_{2}+2 \mathrm{H}_{2} \mathrm{O}+2 \mathrm{HCl}=\mathrm{N}_{2} \mathrm{H}_{4} \cdot 2 \mathrm{HCl}+2 \mathrm{C}_{6} \mathrm{H}_{5} \mathrm{CHO}$.

The monohydrochloride, $\mathrm{N}_{2} \mathrm{H}_{4} . \mathrm{HCl}$, is obtained in long needles by heating the dihydrochloride to $140^{\circ}$. Prof Curtius recommends heating the dihydrochloride in an apparatus heated by vapour of xylene, until no further loss of weight occurs.

The dihydrobromide, $\mathrm{N}_{2} \mathrm{H}_{4} \cdot 2 \mathrm{HBr}$, may be prepared by direct evaporation of a mixture of hydrazine hydrate and hydrobromic acid; but if an alcoholic solution of the hydrate is employed, curiously enough the monohydrobromide separates on the addition of ether. If the pure hydrate is added to excess of liquid bromine, the substarce decomposes completely with liberation of nitrogen and hydrobromic acid gases, nothing but the excess of bromine remaining. But if the bromine is allowed to act upon the hydrate suspended in chloroform, the monohydrobromide separates as a white mass of crystals, nitrogen being also evolved.

$$
5\left(\mathrm{~N}_{2} \mathrm{H}_{4} \cdot \mathrm{H}_{2} \mathrm{O}\right)+2 \mathrm{Br}_{2}=4\left(\mathrm{~N}_{2} \mathrm{H}_{4} \cdot \mathrm{HBr}\right)+{ }_{5} \mathrm{H}_{2} \mathrm{O}+\mathrm{N}_{2} \text {. }
$$

Recrystallized from alcohol, the mono-salt may be obtained in large prisms.

The dihydriodide, $\mathrm{N}_{2} \mathrm{H}_{4} \cdot 2 \mathrm{HI}$, is only obtainable by one method, the decomposition of the benzalazine above mentioned with fuming hydriodic acid. It is singular that none of the methods applicable to the fluoride, chloride, and bromide yield it. When tincture of iodine is added to a dilute alcoholic solution of hydrazine hydrate, the colour disappears completely, in accordance with the quantitative reaction symbolized by the following equation :-

$$
5\left(\mathrm{~N}_{2} \mathrm{H}_{4} \cdot \mathrm{H}_{2} \mathrm{O}\right)+2 \mathrm{I}_{2}=4\left(\mathrm{~N}_{2} \mathrm{H}_{4} \cdot \mathrm{HI}\right)+{ }_{5} \mathrm{H}_{2} \mathrm{O}+\mathrm{N}_{2} .
$$

Nitrogen is evolved, and if the addition of iodine is continued until a permanent coloration is afforded, colourless prismatic crystals of the monohydriodide are obtained on evaporation. These crystals melt at $127^{\circ}$, and in doing so detonate violently. The reaction of hydrazine with iodine may be used volumetrically to estimate the amount of the base in a solution.

In addition to the above iodides, a third, of the composition $\mathrm{N}_{6} \mathrm{H}_{12} \cdot 2 \mathrm{HI}$, or $3 \mathrm{~N}_{2} \mathrm{H}_{4} \cdot 2 \mathrm{HI}$, is obtained in well-defined crystals when an insufficient amount of iodine to form the monohydriodide is used.

Finally, a series of molecular weight determinations of these halogen salts by Raoult's method, using water as the solvent, have been made, with most interesting results. The mono-salts all give numbers agreeing with the molecular weight $\mathrm{N}_{2} \mathrm{H}_{4} \cdot \mathrm{HR}$, showing that in solution they are dissociated into hydrazine $\mathrm{N}_{2} \mathrm{H}_{4}$, and the acid $\mathrm{HR}$. The tri-iodide yields numbers corresponding to $3 \mathrm{~N}_{2} \mathrm{H}_{4} \cdot 2 \mathrm{HI}$, a fact which appears to indicate a dissociation into three molecules of $\mathrm{N}_{2} \mathrm{H}_{4}$, and two molecules of HI. Similarly the sulphate gives values corresponding to $\mathrm{N}_{2} \mathrm{H}_{4} \cdot \mathrm{H}_{2} \mathrm{SO}_{4}$, pointing to its dissociation into separate molecules of $\mathrm{N}_{2} \mathrm{H}_{4}$ and $\mathrm{H}_{2} \mathrm{SO}_{4}$. The di-salts afford results indicating a molecular weight $\mathrm{N}_{2} \mathrm{H}_{4} \cdot 2 \mathrm{HR}$, as if there were a dissociation of the kind $\begin{aligned} & \mathrm{NH}_{3} \\ & \mathrm{NH}_{3} \mid \mathrm{I}\end{aligned}$. The fluoride appears to behave abnormally, yielding numbers corresponding to $\frac{\mathrm{N}_{2} \mathrm{H}_{4} \cdot 2 \mathrm{HF}}{2}$, as if the hydrofluoric acid liberated in the dissociation possessed the constitution $\mathrm{H}_{2} \mathrm{~F}_{2}$.

\section{A. E. TutTon.}

